\title{
Some Thoughts from Your Publisher
}

While the current situation in the world is troubling everyone, and there is much talk about globalization and an apparent and imminent clash of cultures, it is perhaps an appropriate time to share some of our thoughts on our own publishing future at a time of considerable economic uncertainty.

The publishing house of Karger, independent since its founding some 112 years ago, and entirely self-financing, will endeavor to maintain its position. As the number of Scientific, Technical and Medical Publishers consolidate into a few large firms, Karger is proud to remain independent and to continue its cooperative policy, also with various Internet business partners. We believe this to be in the best interest of the scientific community.

As well as remaining in close contact with our established offices worldwide, we are strengthening our stance with a new presence in Beijing and in St. Petersburg, and with a substantial joint venture in the Middle East. Our independence allows us to make publishing decisions based on longer-term considerations and scientific merit, rather than on investment returns in the immediate future.

The quality of our publishing program depends on you - authors, editors, reviewers and readers - and it is to you that we acknowledge our indebtedness with gratitude. We work hard to maintain first-class customer service, fair pricing and sophisticated user-friendly software.

We recognize that as publishers, we play a significant role in the chain of information transfer for education and research, thus helping to bring the world of science closer. We shall not be diverted from this role, and we thank you for your very much appreciated past and future support.

Thomas Karger

Steven Karger

\section{KARGER}

(c) 2002 S. Karger AG, Basel 